\title{
CULTURA FEIRANTE DE INFORMAÇÃO: UM RELATO DE CAMPO SOBRE AS FEIRAS DE LIVRO DO RIO DE JANEIRO
}

\author{
CULTURA FERIANTE DE INFORMACIÓN: \\ UN RELATO DE CAMPO SOBRE LAS FERIAS \\ DEL LIBROS DE RIO DE JANEIRO
}

\author{
Amanda Salomão* \\ Gustavo Silva Saldanha**
}

\begin{abstract}
RESUMO
Introdução: considera-se o universo das feiras de livro como espaços que proporcionam não apenas a democratização e o incentivo ao contato com o livro e à leitura, como também evidenciam práticas informacionais por meio da apropriação e mediação sociotécnica do saber, resultando em uma cultura informacional distinta e singular no locus das feiras. Objetivo: analisar a relação entre a construção simbólica, a circulação e a apropriação dos saberes a partir de duas feiras de livro da cidade do Rio de Janeiro: Primavera dos Livros, promovida pela Liga Brasileira de Editoras (LIBRE) e as Feiras de Livro de iniciativa da Associação Brasileira do Livro (ABL). Metodologia: intervenção, a partir de abordagem qualitativa, nos anos de 2014 e 2015, em duas feiras da cidade do Rio de janeiro, tendo por base aportes do método etnográfico. Buscou-se observar as práticas e trocas informacionais ocorridas no espaço da feira, dialogar com seus "habitantes", enfatizando as mediações sociotecnológicas vivenciadas por seus atores e artefatos. Resultados: a apropriação do espaço-tempo propiciada pelas feiras de livros, sob o ponto de vista simbólico, evidencia a relação dos indivíduos com os objetos estruturados no locus da feira. Reconhece-se no estudo a atribuição interativa de uma rede de significados aos elementos e características do espaço, sendo o livro e a feira, por exemplo, objetos de construção-apropriação simbólica do saber para os integranets dessa cultura feirante. Conclusões: as feiras agem como um outro ambiente de produção, organização e disseminação do conhecimento, diferente daqueles vivenciados em arquivos, museus e bibliotecas, uma vez que o saber e a mediação da informação ocorrem de maneira distinta das formas históricas de tais centros, com foco em uma intensa relação entre a oralidade e a multiplicidade tecnológica.
\end{abstract}

Palavras-chave: Feira de livro. Cultura feirante de informação. Mediação. Artefato sociotécnico. Cultural informacional.

\footnotetext{
* Bacharel em Biblioteconomia pela Universidade Federal do Estado do Rio de Janeiro (UNIRIO). E-mail amandachrisalomao@msn.com.

** Doutor em Ciência da Informação pelo PPGCI IBICT/UFRJ. Professor da Universidade Federal do Estado do Rio de Janeiro (UNIRIO). . E-mail:saldanhaquim@gmail.com.
} 


\section{INTRODUÇÃO}

A palavra "feira", em seu sentido amplo, pode vir a suscitar múltiplos significados e definições. Balbúrdia e confusão, no sentido figurado; mercado público ou comércio, em sentido denotativo, são apenas alguns exemplos do modo como o termo é empregado. De acordo com o Dicionário Houaiss da Língua Portuguesa, a palavra "feira" tem sua origem no latim "feria, ae, dia de festa, mais comum no plural, feria, arum, dias consagrados ao repouso, festas, férias"; partindo do latim vulgar, chegamos às noções de "mercado" e "feira" relacionados ao cotidiano do sagrado, uma vez que "os dias de festa religiosa eram aproveitados para comércio no local daquelas manifestações; por via popular." (HOUAISS; FRANCO, 2001 apud SATO, 2012, p. 90).

Para Sato (2012), o termo "feira" ainda consiste na reunião de pessoas, bem como nas interações que aí se constroem, como se representassem uma espécie de evento. Por essa razão, as feiras encontram-se diretamente atreladas ao espaço de sociabilidade que criam. Seja através das feiras livres com sua compra e venda de produtos alimentícios ou, até mesmo, por meio das feiras de livros, um espaço de sociabilidade e circulação da informação é criado naquele locus, de modo a construir mediações sociotecnológicas, bem como significados plurais sob e sobre os objetos que as circundam.

Do ponto de vista conceitual, acredita-se ser este um espaço onde se pode discutir, a partir de Marteleto (1995), uma noção aberta de cultura informacional, conceito nuclear para o presente estudo. Para a autora, o processo de construção da informação compreendido como objeto só se consolida quando se consideram tanto as estruturas materiais e simbólicas de determinado universo cultural - como as feiras, por exemplo, aqui iluminadas -, quanto as relações, práticas e representações de indivíduos cada vez mais mediadas por um modo "informacional" (ou sociotecnológico).

Ainda de acordo com Marteleto (1995), cultura e informação são objetos ligados pela sua própria natureza. A cultura se apresenta como o passo inicial para a construção conceitual da informação abordada como artefato ou como processo que produz e estimula as práticas sociais e informacionais dos 

Janeiro

sujeitos. Assim, a informação se relaciona intrinsecamente com a cultura ao passo que diz respeito não somente ao modo de relação dos sujeitos com a realidade, como também aos artefatos criados pelas interações e práticas sociais, tal como se dá no locus das feiras, de modo que se cria uma cultura informacional.

As feiras compõem uma aberta rede de interações sociais, onde linguagem, discurso, signos, objetos, encontro e trabalho vivenciam o contexto da vida social dos indivíduos que ali vendem, compram, falam, olham, sentem. A feira torna-se um lugar não apenas de consumo, como também, um espaço de sociabilidade, de comunicação verbal, de formação de símbolos e significados, tal como se atuasse como a própria representação de uma festa. Neste âmbito o presente trabalho ganha forma. Considerando-se as múltiplas acepções e finalidades da noção de feira e suas formas históricas no cerne de uma cultura informacional, o artigo busca destacar a importância de uma tipologia-feira em especial: as feiras de livro.

Tendo em vista ainda a relevância das feiras de livro para a democratização do livro e da leitura, bem como a escassez da temática na literatura científica, o presente estudo tem como objetivo suscitar o questionamento sobre as práticas e trocas informacionais ocorridas em seu locus, com ênfase para as mediações sociotecnológicas vivenciadas por seus objetos e atores e para a apropriação simbólica do espaço-tempo da feira. Para tanto, tem-se como foco apresentar um relato de campo acerca da vivência simbólica nas feiras de livro do Rio de Janeiro, tendo por base a Primavera dos Livros, promovida pela Liga Brasileira de Editoras (LIBRE) e as Feiras de Livro de iniciativa da Associação Brasileira do Livro (ABL).

Para o presente estudo interessa, através de aproximações etnográficas que permitem relacionar simbolismo e vivência, compreender as conexões entre a construção simbólica do espaço-tempo e a circulação e a apropriação dos saberes a partir de experiências urbanas, tendo como locus as feiras de livro e sua produção de significados junto aos artefatos informacionais. No plano qualitativo do estudo, as chamadas aproximações etnográficas indicadas pautam-se na observação direta da vivência das feiras, acompanhando, em 
diferentes dias e turnos, o seu funcionamento, dialogando com seus "habitantes" e seus "frequentadores", registrando seus gestos e rituais.

A justificativa para tal elaboração do objeto de estudo e de sua população pesquisável está na intrínseca relação do ambiente abordado e suas vivências no plano de uma cultura informacional. Em outros termos, encontramos nas feiras a conjugação de elementos centrais que constituem o olhar epistêmico biblioteconômico-informacional, tais como tecnologias da linguagem, práticas de trocas informacionais, instituições e institucionalizações da informação, profissionais da informação, bem como experiências compartilhadas de informação. No entanto, ausentam-se tais contextos (as feiras) de parte considerável da reflexão do campo científico em questão.

A temática não é muito abordada na área de Ciências Humanas e Sociais, sobretudo em Biblioteconomia e Ciência da Informação. Considerando-se as consultas preliminares realizadas no Banco Digital de Teses e Dissertações do Instituto Brasileiro de Informação em Ciência e Tecnologia (BDTD-IBICT), no período de 2014, 2015 e 2016, bem como nos periódicos da área de Ciência da Informação, foi possível observar a escassez de material publicado sobre a temática feira de livro. Além disso, a literatura científica em geral também não procura abordar o referido tema. Quando muito, nas poucas vezes em que a produção sobre as feiras é encontrada, está relacionada, em sua maioria, à Feira do Livro de Porto Alegre, promovida pela Câmara Rio-Grandense do Livro e com ênfase para as áreas de Administração e Educação.

Sabe-se que os muitos espaços onde as feiras de livro acontecem, tal como a Primavera dos Livros e as Feiras do Centro do Rio de Janeiro, são palco de distintas esferas de mediação (envolvendo relações sociotécnica) de apropriação do saber, que acabam por proporcionar o diálogo entre o mundo impresso e digital, seja através de um livro ou de um celular, por exemplo. Desse modo, a importância das feiras de livros vai muito além de sua atuação nas searas da popularização e da democratização do livro e do incentive à leitura. $\mathrm{O}$ ambiente informal proporcionado por elas abre caminho para novas formas de apropriação simbólica do locus onde encontram-se inseridas, 
propiciando, também, outras formas de construção dos sabers.

Como parte da etapa do processo de pesquisa, realizou-se o mapeamento da produção científica sobre as feiras, num contexto geral, no já mencionado BDTD-IBICT, a fim de identificar a definição dos diversos tipos de feiras e como a mesma é abordada nas áreas de Ciências Humanas e Sociais Aplicadas, tanto no plano metodológico, quanto no plano teórico. Realizou-se também, para fins de referencial teórico, a pesquisa bibliográfica na literatura científica de áreas afins à Ciência da Informação, sob o enfoque biblioteconômico-informacional. Assim, a pesquisa apresenta o resultado da revisão de literatura dos seguintes autores: Almeida (2008), Ferraz (2006), Horodyski (2014), Leite (2015), Marteleto (1995), Massola (2015), Mazzarotto (2014), Vasconcellos (2015), Retiere (2014), Saldanha (2014), Sato (2012) e Tonet (2004).

Nestes termos, a primeira parte do artigo debate conceitualmente a noção de feira, com ênfase para seus múltiplos tipos, finalidades e significados. O estudo alerta que este posicionamento discursivo, de fundo didáticohistórico, se dá em razão das estratégias preliminares de estudo, que demarcaram a ausência da reflexão sobre a feira, em suas mais diferentes abordagens, no escopo dos estudos informacionais. Em seguida, abordar-se-á um breve histórico das feiras, de modo a discorrer sobre o seu surgimento em sentido estritamente sociotemporal. Posteriormente, apresentar-se-á a finalidade das feiras de livro do Rio de Janeiro, com destaque para a Primavera dos Livros e para as Feiras promovidas pela $A B L$, de modo a contextualizar aspectos da cultura feirante de informação ali identificada. Por fim, chega-se ao tema central do presente artigo: o relato de campo sobre a vivência em feiras de livro do Rio de Janeiro, ressaltando as mediações sociotecnológicas tecidas no locus das feiras, bem como sua expressão da ocupação do espaço urbano. Por fim, o artigo pretende lançar luz sobre as considerações realizadas ao longo das visitas às feiras de livro. 


\section{2 "VISITA" À NOÇÃO DE FEIRA}

Em um contexto geral, as acepções da palavra "feira" acabam sempre por aludir à algum tipo de comércio que reúne vendedores e compradores em determinada hora e local. Nesse sentido, um dos tipos mais comuns e conhecidos de feira da qual se pode falar são as "feiras livres", responsáveis por comercializar nas ruas e a um preço mais acessível alimentos hortifrutigranjeiros, em sua maioria.

No entanto, existe uma gama de outras espécies de feiras que também envolvem o comércio de bens de consumo, porém com objetivos diferentes. Para citar alguns exemplos, existem as feiras agroecológicas, que diferem das feiras livres convencionais por serem criadas e administradas com a cogestão de agricultores familiares, conforme aponta Mazzarotto (2014). Segundo o autor, as feiras agroecológicas geralmente produzem os alimentos que comercializam, bem como conhecem sua origem e a maneira como os mesmos foram produzidos.

Tem-se também a feira do produtor que, de acordo com Retiere (2014), pode ser entendida como um tipo de comércio feirante reservado aos produtores, proibindo a presença de comerciantes revendedores. Com base na autora, a feira do produtor encontra sua razão de ser na comercialização de produtos agrícolas, cujo foco está mais na valorização da produção local do que na garantia de produtos frescos baratos.

Embora assumam múltiplas finalidades, o termo feira ainda acaba quase sempre por estar associado ao comércio de produtos alimentícios, sejam eles orgânicos ou não, de modo que a mesma é popularmente reconhecida como um mercado de alimentos. Contudo, a definição e a aplicação da noção vão muito além do comércio alimentício.

Por exemplo, tem-se a ocorrência de muitas feiras de artesanato, caracterizadas pela iniciativa de artesãos que encontram nas feiras um local para expor seus produtos, tornando-se um evento comercial das mais variadas artes (TONET, 2004). Além disso, como aponta Horodyski (2014), as feiras de artesanato podem atuar também, em muitas vezes, como um evento associado 

Janeiro

a capacidade de estimular os moradores de determinada cidade a conhecerem a cultura local, adotando uma finalidade turística.

Reconhece-se aqui, ainda, em outra dimensão, as feiras de ciências. Sua principal proposta é expor um determinado conjunto de informações a um público, de modo a promover a disseminação da produção científica, segundo Vasconcellos (2015). Assim, tornam-se um meio para a popularização da ciência, de forma a integrar o tema escolhido com a realidade da comunidade ao qual esteja inserido.

Além dos diversos tipos de feiras mencionados, identifica-se também as feiras de livro, objeto do presente estudo, que têm como finalidade possibilitar a compra e venda de livros à preços acessíveis, de acordo com Ferraz (2006). Nessa perspectiva, essas feiras, uma vez que, em sua maioria, disponibilizam livros à preços mais acessíveis, acabam por atuar como um instrumento de popularização e democratização do livro e de incentivo à leitura.

Conforme aponta Massola (2015), a feira de livro pode ser compreendida não apenas como um local para comercialização de livros e outros bens materiais, mas também como um espaço de sociabilidade e entretenimento, que reúne e viabiliza o encontro de estudantes, professores, turistas, visitantes, expositores, livreiros, autores, entre outros públicos associados ao mundo literário.

Lá, ainda, pode-se encontrar representantes de inúmeras editoras, bem como da mídia, tais como jornal, televisão e rádio, que tem por intuito divulgar as atividades desempenhadas pelas feiras de livro. Nesse sentido, cabe dizer que a feira pode vir a acoplar e reunir ações paralelas, congregando outros eventos educativos e musicais, além dos literários (MASSOLA, 2015).

Do ponto de vista histórico, para Leite (2015), as feiras encontram-se diretamente ligadas a um conjunto de práticas econômicas populares, originando-se sob a forma de atividades comerciais livres destinadas à comercialização de produtos alimentícios. Assim, segundo Sato (2012), a feira pode ser situada historicamente na Europa do início do século IX, no qual os mercados existiam com o objetivo de suprir a comunidade local com os 

Janeiro

produtos necessários à sua sobrevivência, tornando-se um dos modelos mais expressivos de organização econômica da época medieval.

Ainda de acordo com Sato (2012), o auge das feiras se deu por volta dos séculos XII e XIII, também na Europa. Eram consideradas como espaços públicos de compra e venda, de modo a abarcar um grande número de pessoas e produtos, independentemente das necessidades locais. Com isso, as feiras acabavam por ter uma importância de destaque para a vida econômica europeia, uma vez que reavivaram o comércio através do renascimento comercial, atraindo mercadores de diversas regiões.

Assim, ainda segundo a autora, as feiras da Idade Média podem ser compreendidas como grandes reuniões de comerciantes de várias regiões europeias que comercializavam os mais diversos produtos. Por essa razão, ocorriam semanalmente, com seu círculo de atração limitado, bem como tendo suas atividades restritas às pequenas operações de varejo (SATO, 2012).

Além disso, com base em Leite (2015) e Sato (2012), as feiras contribuíram consideravelmente não apenas para a economia internacional da época, como também desempenharam um papel social e cultural essenciais para a sociedade medieval, visto que tais reuniões poderiam ser consideradas como um dos poucos momentos de sociabilidade durante a Idade Média.

Para Leite (2015), o mercador ambulante era o elo da rede comercial da Europa feudal, responsável por seguir de feira em feira comprando em uma para vender em outra. De acordo com o autor, a partir do século XII, tendo em vista a evolução do transporte fluvial, as feiras livres locais passaram a atender diretamente o consumidor, uma vez que o trânsito e o comércio de mercadorias fora facilitado.

Já a partir do século XIV, entretanto, as feiras passaram a ser destinadas somente à exposição de amostras dos produtos, visto que o custo com seu transporte se tornou oneroso, o que acabou por desestimular a atividade. Ademais, a tecnologia das comunicações fora responsável por promover nova alteração, transformando as vendas em um comércio realizado por correspondência, diminuindo ainda mais a necessidade de se realizar feiras, fazendo com que as mesmas assumissem um papel secundário no 
comércio europeu (LEITE, 2015).

\section{PROCEDIMENTOS METODOLÓGICOS}

O método do estudo, de ordem qualitativa, baseia-se na pesquisa de campo, através de aportes do método etnográfico, a partir da vivência do pesquisador nas feiras de livro, por meio de visitas e intervenções, desde seu início ao encerramento diário, com uso de fotografias, diálogos e entrevistas, a fim de identificar a feira enquanto locus de produção simbólica e de compartilhamento de práticas de uma cultura informacional.

Nesse sentido, em um primeiro momento, visitou-se a $14^{a}$ edição da Primavera dos Livros, ocorrida nos jardins do Museu da República, Rio de Janeiro, nos dias 01 (sábado) e 02 (domingo) de novembro de 2014. Os horários oscilaram entre $14 \mathrm{~h} 30 \mathrm{~min}$ às $17 \mathrm{~h} 30 \mathrm{~min}$ no primeiro dia e $18 \mathrm{~h} 30 \mathrm{~min}$ às 20 h00 no segundo.

$\mathrm{Na}$ Primavera dos Livros, buscou-se observar as inúmeras práticas informacionais que ocorriam em seu locus, fazendo uso de fotografias como recurso para captação das mediações humanas e tecnológicas entre os objetos da feira e os indivíduos que por ali circulavam. Observou-se também o público da "Primavera" e como o mesmo se relacionava com a feira, seus objetos e o espaço do Museu da República. Isto é, se aproveitavam o local para ler os livros comprados, mexer no celular, interagir com outras atividades do evento, como as mesas redondas e os saraus, por exemplo.

Quanto à Feira de Livros do Centro do Rio de Janeiro, localizada na Praça da Cinelândia, realizou-se intervenção no dia 15 de maio de 2015, de $8 \mathrm{~h} 30 \mathrm{~min}$, quando as barracas ainda estavam sendo montadas, às $18 \mathrm{~h} 00$, no momento em que o movimento já não era tão intenso.

$\mathrm{Na}$ feira, tal como na "Primavera", buscou-se observar, lançando mão também da fotografia como recurso, as práticas de mediação humana, à exemplos de pessoas lendo ou falando sobre um livro com alguém; e tecnológica, quando havia interação entre os aparelhos tecnológicos e os livros, como tirar foto dos mesmos ou observá-los enquanto os indivíduos carregavam um celular ou uma câmera na mão. 
Além das fotografias, foram realizadas entrevistas com os feirantes, com o intuito de saber como eles chegaram às feiras, suas experiências durante o período em que trabalhavam com o evento e se tinham alguma lembrança especial ao longo desses anos de atuação. Como recurso de coleta, adotou-se o gravador de voz, para registrar as perguntas realizadas e as respostas dos entrevistados - junto do ato, foi registrada a assinatura de termo de autorização livre e consentido para o uso dos dados. Por fim, concomitante ao período de intervenção nas duas feiras analisadas, elaboraram-se inúmeras folhas de campo a fim de analisar e discutir os dados coletados.

\section{RESULTADOS E DISCUSSÃO}

Os dados sobre as duas feiras analisadas, bem como das entidades que as promovem, são aqui apresentados de modo a discorrer sobre seu surgimento, características e objetivos, contextualizando o cenário investigado. Ainda, tem-se como escopo relatar as experiências vivenciadas na Primavera dos Livros, no ano de 2014, e nas Feiras do Centro do Rio de Janeiro, já no ano de 2015.

\subsection{Cultura Feirante de Informação: Primavera dos Livros e as Feiras itinerantes}

Há muitas décadas, as feiras de livro ocupam logradouros públicos, como praças e museus, por exemplo. Desde o seu início em território nacional, na década de 1950, as feiras sempre tiveram como foco principal incentivar o livro e a leitura, instaurando-se em locais de fácil acesso, bem como vendendo- a preços módicos, a fim de alcançar quaisquer camadas sociais e democratizar o acesso ao livro, que sempre fora visto como objeto de consumo das classes altas (FERRAZ, 2006).

Nessa perspectiva, no Rio de Janeiro, o recorte geográfico primário do presente estudo, as feiras de livro já ocorrem também há muitas décadas. Segundo dados da Revista do Livro (1967), as feiras existem pelo menos desde 1957, sendo promovidas pelo Instituto Brasileiro do Livro (INL) e incluídas no contexto da "Semana do Livro", evento oferecido em homenagem 
ao aniversário de Machado de Assis, na semana de 20 a 26 de junho.

A feira fora inaugurada em 20 de junho de 1957, já na II Semana do Livro. Nessa semana, realizava-se uma feira de livros na Praça da Cinelândia, a qual se prolongava por quinze dias, indo em seguida para a Praça Saens Peña. Seu intuito principal era promover e estimular o gosto pela leitura através da venda de livros a baixo custo, configurando-se em uma das primeiras feiras de livros instauradas no Rio de Janeiro (REVISTA DO LIVRO, 1967).

Nesse sentido, diante do sempre existente papel social desempenhado pelas feiras, ao promover o incentivo às atividades ligadas tanto à leitura quanto aos livros, encontra-se nelas o livro "indo ao povo", às mais diversas camadas sociais, democratizando-se e incutindo o hábito da leitura. (REVISTA DO LIVRO, 1967).

Até os dias atuais existem inúmeras instituições que apoiam e promovem iniciativas relacionadas às feiras de livros, tais como: Câmara Brasileira do Livro (CBL), Fundação Nacional do Livro Infantil e Juvenil (FNLIJ), Fundação Biblioteca Nacional (FBN), Associação Brasileira do Livro (ABL) e Liga Brasileira de Editoras (LIBRE). Contudo, das instituições mencionadas, as duas últimas se destacam na cidade do Rio de Janeiro por promoverem feiras correntes de livros em locais gratuitos e de fácil acesso.

Por essa razão, durante os anos de 2014 e 2015, realizou-se as intervenções em duas feiras de livros: a Primavera dos Livros, de iniciativa da LIBRE, e as feiras do Centro do Rio de Janeiro, promovidas pela ABL, de modo a suscitar o questionamento acerca da cultura informacional desses locus.

\section{- Primavera dos Livros}

A Primavera dos Livros pode ser caracterizada como um evento realizado anualmente pela Liga Brasileira de Editoras, com o intuito principal de disseminar e estimular o gosto pela leitura através de editoras independentes de pequeno e médio porte, que visam alcançar um espaço maior dentro do mercado editorial brasileiro.

A primeira edição desta feira nasceu em 2001, na cidade do Rio de Janeiro, originando-se a partir do diálogo entre editores cuja convicção recai 
sobre o livro como artefato capaz de alterar o panorama intelectual do país (LIBRE, 2014). Com isso, a Primavera atua como uma "festa", na qual leitores, autores e editores se encontram, tendo o livro como personagem principal.

Nessa perspectiva, no início do século XXI, a avaliação de que o mercado editorial estava se tornando cada vez mais pautado na lógica do bestseller levou um grupo de editores a se juntar em torno da realização de uma feira de livro que apresentasse ao público leitor uma produção alternativa a essa tendência, tendo por base a venda da produção literária comercializada por pequenas e médias editoras (LIBRE, 2014). Por essa razão, a Primavera dos Livros vem atuando, ao mesmo tempo, como um espaço de exposição e venda dessa produção editorial independente, bem como na defesa de políticas públicas e de mercado que valorizam essa diferença.

Dessa forma, cabe ressaltar que a LIBRE se entende como transmissora cultural, de modo a considerar a Primavera dos Livros não apenas como um evento cultural e comercial, mas também como um catalisador de forças e de energias para preservar, junto ao seu público, a difusão da leitura e do acesso ao livro. Assim, ao promover a produção editorial independente, a instituição acaba por cumprir, em sua visão, cada vez mais, seu papel cultural, tanto literário quanto ensaístico, para crianças e adultos.

Ao longo dessa década, o principal objetivo da Primavera dos Livros tem sido o de incorporar o livro às necessidades básicas da população, de modo a propiciar acesso à cultura, ao lazer e ao conhecimento a partir da promoção do hábito de leitura. Para tanto, o evento ocorre durante quatro dias, com acesso livre e gratuito ao espaço onde é realizado, oferecendo não apenas livros a preços reduzidos, como também uma ampla programação cultural, a saber: encontro com autores e editores, atividades infantis relacionadas ao livro e à leitura, debates, mesas redondas, saraus, entre outros.

Ainda, a Primavera dos Livros já teve várias "moradas" no Rio de Janeiro. Inicialmente, a feira se deu no Jockey Club e no Jardim Botânico. Logo após, ocupou os Armazéns do Cais do Porto e, atualmente, a "festa" acontece nos jardins do Museu da República. 
Em 2014, ano da intervenção na feira, sua $14^{a}$ edição teve também como palco os jardins do Museu da República, funcionando das $10 \mathrm{~h}$ às $22 \mathrm{~h}$. Nesta edição, a Primavera teve seu início em uma quinta-feira, 30 de outubro, e seu término no domingo, 02 de novembro, com destaque para a homenagem aos 450 da fundação da cidade do Rio de Janeiro.

\section{- Feiras itinerantes da Associação Brasileira do Livro}

As feiras de livros que ocorrem no Centro do Rio de Janeiro, promovidas pela Associação Brasileira do Livro, podem ser consideradas como itinerantes, uma vez que ocupam sempre um território diferente, geralmente praças públicas, por um curto período de tempo. Seu objetivo principal, desde sua criação, é promover o livro e o gosto pela leitura, bem como democratizar seu acesso, aproximando-o das mais diversas camadas sociais.

Nestes termos, a ABL, considerada como uma entidade privada sem fins lucrativos, organiza as feiras de livro nas praças da cidade do Rio de Janeiro, a fim de divulgar o livro e promover seu acesso. O interesse primordial da Associação é realizar uma "exposição literária", com o intuito de alcançar o maior número de pessoas menos familiarizadas com o livro, de forma a suscitar e incentivar o hábito de leitura.

Ainda, as feiras de livro realizadas pela Associação Brasileira do Livro buscam oferecer ao público descontos de no mínimo $20 \%$ em todas as obras expostas, bem como várias ofertas e promoções para todas as faixas etárias, além de livros raros e os últimos lançamentos editoriais das mais conceituadas editoras do país.

Segundo dados da $A B L$, as feiras de livro que ocorrem nas praças do Rio de Janeiro recebem centenas de visitantes diariamente, de todas as faixas etárias, em busca de livros de ficção, estudo, clássicos, intelectuais, entre outros, transformando as feiras itinerantes em um acontecimento cultural na cidade (ASSOCIAÇÃO BRASILEIRA DO LIVRO, 2015).

A fundação da $A B L$ tem como pano de fundo a década de 1950, em especial o ano de 1955, quando um vereador carioca expôs seus livros em uma barraca armada em frente à Câmara Municipal. Alguns livreiros, 
admirando sua iniciativa, resolveram, em um grupo de seis, aprovar a ideia, e tempos depois fizeram uma mostra semelhante em condições bem precárias. Contudo, a exposição acabou por se tornar um sucesso de vendas, possibilitando a organização da $1^{\text {a }}$ Feira do Livro, realizada na Praça da Cinelândia em outubro de 1955, já contando com quarenta e duas barracas (ASSOCIAÇÃO BRASILEIRA DO LIVRO, 2015).

Em 1957, visto o sucesso de vendas ocasionado pelas feiras de livro, o grupo de associados resolveu fundar a Associação Brasileira do Livro, a fim de dar mais formalidade à organização das feiras nas praças da cidade do Rio Janeiro. Dessa forma, a $A B L$ vem desenvolvendo ao longo dessas décadas um trabalho de democratização do livro, possibilitando, através dos preços baixos das obras, o acesso às populações de baixa renda, bem como um espaço informal de convivência e sociabilidade por entre os livreiros e seus visitantes.

Assim, ainda que a Associação Brasileira do Livro organize feiras de livro em diversos pontos do Rio de Janeiro, ao longo do ano de 2015, realizaram-se visitas e intervenções em feiras situadas no Centro Histórico da cidade, com o intuito de observar as inúmeras práticas informacionais ocorridas a partir de mediações tecnológicas e sociais, bem como a ocupação simbólica do espaço público por esses eventos literários. Desse modo, tendo em vista que a feira ocupa praças, de modo geral, por cerca de um mês, foram realizadas intervenções durante o dia 15 de maio de 2015 na feira da Praça da Cinelândia, localizada no centro da cidade do Rio de Janeiro.

4.2 Cultura Informacional na Feira: um relato de campo entre as feiras de livro no Rio de Janeiro

As feiras de livro, desde sua origem, surgiram como um instrumento capaz de proporcionar a democratização do acesso ao livro e à cultura, através da venda dos mesmos à preços acessíveis às mais diversas camadas sociais.

No Brasil, ao longo de mais de cinco décadas, as feiras continuam a desempenhar essa função, exceto que, hoje em dia, elas atuam não apenas como fornecedora de cultura e informação, mas também como mediadora de toda a massa informacional que se encontra disponível em seu locus. 
Para Almeida (2008), os processos de mediação se estabelecem, além dos níveis institucional e profissional, como as bibliotecas, por exemplo, também segundo um contexto sociossimbólico, a partir da compreensão do papel da cultura e da linguagem como espécies de mediação. Desse modo, por meio dos artefatos sociotécnicos que as circundam, as feiras possibilitam a mediação no que tange à circulação e apropriação da informação, bem como a atribuição de significados distintos aos objetos presentes nas mesmas (SALDANHA, 2014).

Tais considerações são corroboradas por Marteleto (1995), para quem a ideia de cultura informacional engloba a noção de informação como artefato cultural, como forma de criação e instituição dos significados ou ainda como modo de produção, controle e distribuição social dos bens simbólicos.

Com efeito, a cultura informacional acaba por se relacionar com a construção do objeto informação, uma vez que os bens culturais - artefatos da feira que promovem a significação, mediação e apropriação da informação produzidos como matéria informacional não são compartilhados socialmente, mas sim, distribuídos. Isto é, dependem das atividades de produção, reprodução, transmissão e aquisição, a partir do qual os sujeitos precisam estar integrados em um ambiente onde haja práticas e relações sociais, a fim de possibilitar a significação e apropriação de informação mediados por indivíduos ou artefatos.

Nesse sentido, nas feiras de livro, muitos espaços de significação podem e são criados, uma vez que inúmeras atividades ocorrem ao mesmo tempo, como o comércio, a montagem das barracas, a interação e o relacionamento entre livreiros e entre livreiros e clientes. O próprio relacionamento de um consumidor com um artefato - no caso, o livro -, se torna responsável por criar uma rede de significados (FERRAZ, 2006). Com isso, também a relação entre livros e outros artefatos tecnológicos nas feiras, como um aparelho celular ou uma câmera, por exemplo, no que se diz à apropriação da informação, é capaz de suscitar a criação de significados, lembranças e valor simbólico.

Assim, as práticas informacionais e a apropriação da informação estão presentes em todos os espaços da feira, seja nos jardins do Museu da 
República ou nas praças públicas do Centro Histórico do Rio de Janeiro, estimulando o reconhecimento e a atribuição de significados aos inúmeros artefatos que compõem as feiras, sendo este o livro, o livreiro ou a câmera.

Em vista disso, a experiência de intervenção nas feiras de livro no Rio de Janeiro ilustra não apenas as práticas informacionais ocorridas em seu locus, mas também a circulação e a apropriação da informação que se dá por meio das mediações humanas e tecnológicas vivenciadas em seus espaços, seja através de uma foto tirada por um celular ou, até mesmo, pela contação de histórias.

Os dois formatos estão em permanente diálogo. Impresso e digital, no mundo contemporâneo, caminham juntos, de modo a denotar a experiência de práticas informacionais e apropriação da informação em suas múltiplas formas. A pesquisa, por meio da intervenção na Primavera dos Livros e nas Feiras Itinerantes do Centro, tentou observar justamente a vivência desses diálogos e as inúmeras práticas informacionais, no plano simbólico, experenciadas por seus atores nas feiras de livro do Rio de Janeiro. Buscou-se, com isso, acompanhar a movimentação e os gestos simbólicos de sujeitos, artefatos e suas relações.

\section{- Primavera dos Livros: intervenção sob o enfoque biblioteconômico- informacional}

Em 2014, ano da intervenção na feira, a Primavera dos Livros se deu nos jardins do Museu da República, entre os dias 30 de outubro (quinta-feira) à 02 de novembro (domingo), das $10 \mathrm{~h}$ às $22 \mathrm{~h}$, tendo como tema central a homenagem aos 450 anos da cidade do Rio de Janeiro. Nesse contexto, a intervenção na Primavera foi feita nos dias 01 (sábado) e 02 (domingo) de novembro, em horários alternados entre tarde e noite, a fim de observar como se dava a circulação de pessoas e sua interação com a feira em momentos distintos.

Inicialmente, considerando-se que o Museu da República fora palco de importantes acontecimentos históricos, políticos e sociais que muito contribuíram para história do Brasil, é interessante observar que a utilização do 
seu espaço como locus da Primavera dos Livros, constitui, nos dias do evento, um ambiente de sociabilidade e mediação, com ponteciais elementos sociohistóricos ali envoltos.

Com isso, o Museu da República atua como um atrativo estéticoarquitetônico para a feira literária, uma vez que os visitantes que foram, inicialmente, para uma visita turística, podem vir a gerar um interesse pelas barracas ali expostas e pelas atividades culturais que ocorrem em seu espaço.

Ademais, aqueles que se direcionaram ao Museu com 0 intuito específico de visitar à feira, puderam contar com um amplo espaço para exercer outras atividades, tais como: comer, se exercitar, participar do sarau, mesas de debate, sentar, conhecer o ambiente, fotografar, conversar, ler e andar pelos jardins. É possível, dessa forma, considerar a Primavera dos Livros como um importante espaço de sociabilidade, uma vez que proporciona e promove a interação e troca de ideias por entre seus múltiplos indivíduos e objetos.

No dia 01 de novembro, a chegada à feira se deu por volta das 14h30min, e se pôde notar uma considerável quantidade de visitantes que circulavam pelo local. Assim, foi possível perceber uma pluralidade de identidades que percorria os jardins do Museu. Acredita-se que a diversidade sociocultural observada (de gênero, de idade, de raça, por exemplo) nos jardins do Museu fora possibilitada graças à gratuidade do evento, que acabou por promover certa desburocratização e democratização do espaço-tempo a partir da feira-festa.

Nesse plano, no decorrer da intervenção na feira, foi possível observar a relação existente entre os artefatos - tanto impressos quanto eletrônicos e digitais - e os visitantes que circulavam por entre as barracas. Em sua maioria, as pessoas portavam um aparelho celular nas mãos, denotando a ampla relevância desses objetos para o contexto da sociedade atual. Entretanto, o significativo número de visitantes na feira, bem como o aglomerado que se formava nas barracas, acabou por demonstrar que o interesse pelos impressos se conjugava com o uso intermitente dos aparelhos celulares.

Mesmo diante do desenvolvimento das tecnologias de informação e 
comunicação e o potencial de facilitação de relações info-comunicacionais permitido por tal avanço, a intervenção na Primavera demonstrou que isso não diminui em nada o interesse dos indivíduos pelos impressos (e a convivência de tais artefactualiades). Era possível ver as pessoas falando ao celular ou conectadas à internet ao mesmo tempo em que suas mãos permaneciam cheias de sacolas repletas de livros impressos. Ainda, muitas pessoas portavam celulares ou câmeras nas mãos ao mesmo tempo em que folheavam um livro (ou utilizavam os mesmos para fotografar o espaço-tempo dinâmico em curso).

As figuras 1 e 2 abaixo representam a interação entre os artefatos sociotecnológicos que se apresentam na feira, ilustrando a coexistência entre os elementos identificados e reconhecidos através da mediação, bem como a vivência de práticas informacionais simbólicas no locus das feiras.

FIGURAS 1 e 2. Primavera dos Livros - 01 de novembro de 2014

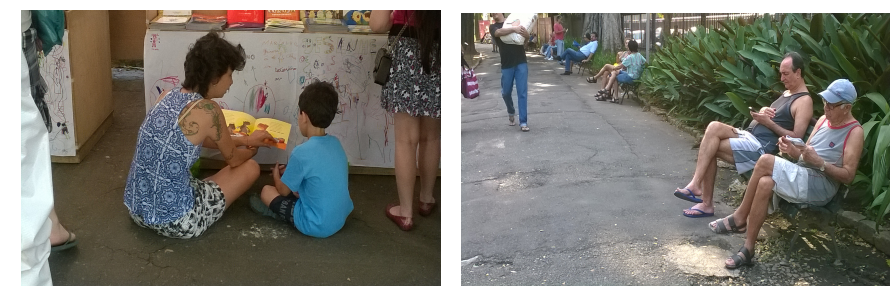

Fonte: Banco de Imagens Ecce Liber

Assim, é relevante considerar a Primavera dos Livros como um evento capaz de promover a produção simbólica de um certo espaço-tempo em uma cultura informacional por parte dos livreiros e dos artefatos, uma vez que atua como palco de circulação do conhecimento e apropriação do saber, possibilitando a atribuição de significados aos objetos, previamente reconhecidos, que se encontram ali expostos.

De acordo com D'Adesky (1997, p. 307 apud FERRAZ, 2006, p. 122),

[...] o espaço não é somente uma área geográfica, sendo também uma forma de relação com os objetos estruturados numa cultura e, sobretudo, numa rede relacional de representações coletivas que permite aos membros de uma mesma coletividade conceder significados, geralmente reconhecidos, a elementos e características de seu espaço. 
Nesse contexto, a convivência entre os diferentes suportes e as múltiplas identidades ali presentes acaba por desencadear uma rede de representações coletivas, onde cada indivíduo atribui um significado, já reconhecido, aos objetivos estruturados na feira. Desse modo, os livros, os livreiros e o espaço atuam como objetos de apropriação do saber simbólico, uma vez que propiciam a atribuição de significados, seja de cunho afetivo ou intelectual, aos elementos expostos na feira (FERRAZ, 2006).

Com isso, a Primavera desempenha um papel de transformadora social e de receptora das diferenças técnico culturais, uma vez que promove uma percepção plural do espaço-tempo por meio do atrativo dos livros mais baratos e ingressos gratuitos, bem como da possibilidade de uma reafirmação do papel da oralidade como marca da produção do sentido ao lado das tecnologias gráficas (a velha marca simbólico-histórica da feira como lugar da conversa); proporcionando aos seus visitantes, assim, apropriarem-se e reconstruírem os saberes contidos naquele espaço, seja através da mediação via oralidade, via artefatos.

No domingo (02/11/2014), o contato com a feira se iniciou por volta das 18h30min, onde foi possível observar um número menor de pessoas circulando em relação a sábado. Acredita-se que tal fato se deu devido ao horário, já considerado "tarde" para os padrões de um domingo nos grandes centros urbanos brasileiros.

Nesse panorama, observou-se impressões semelhantes às de sábado, onde ainda prevalecia a coexistência entre mediação sociotecnológica, através dos artefatos eletrônicos e digitais e dos lançamentos de livros e debates ocorridos no dia. Por ser o último dia, o preço estava mais baixo. No entanto, não havia muita divergência em relação ao início do evento.

As figuras 3 e 4 ilustram que se notou a mesma interação das pessoas com o espaço de sociabilidade e apropriação do saber, nos quais as mesmas, ainda que rodeadas de impressos, interagiam com artefatos tecnológicos, como os celulares e câmeras. 
FIGURAS 3 e 4. Primavera dos Livros - 02 de novembro de 2014
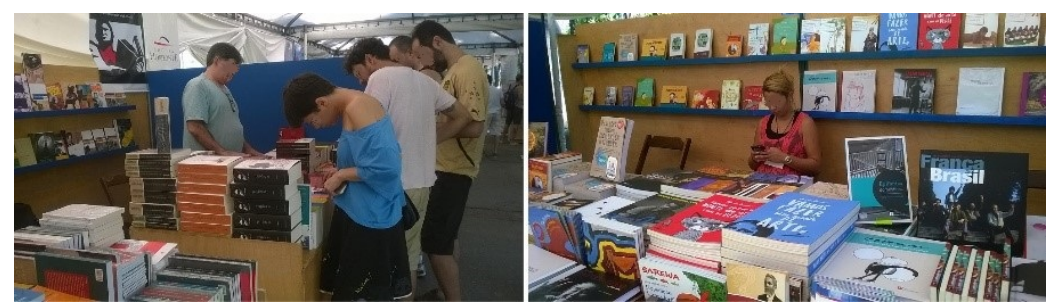

Fonte: Banco de Imagens Ecce Liber

Tendo em vista que o objetivo da intervenção na Primavera fora tentar captar a interação entre os indivíduos e os objetos de apropriação do saber simbólico, ressaltando a mediação sociotecnológica propiciada pelos elementos da feira, tornou-se possível observar as inúmeras representações simbólicas suscitadas nos jardins do Museu da República.

Como ressalta Saldanha (2014, não paginado) no tocante à Primavera dos Livros,

[...] as 'pequenas multidões' se deslocam em vai e vem em torno das barracas repletas de livros, mal tal movimento não diz respeito apenas à procura pelo contato com artefato epistêmico do códice vegetal. A circulação dos saberes aqui, complexa em sua elaboração e manifestação, responde por uma relação entre artefatos e sujeitos como 'metamediadores': é impossível determinar onde começa e onde termina o suposto 'isolamento' entre mediação humana e mediação técnica, entre novas formas e arcaicas ferramentas de mediação artefactual, e novas e arcaicas formas de relação entre mediadores. Entre aparelhos celulares e máquinas fotográficas digitais, centenas e centenas de livros, as 'pequenas multidões' atravessam o dia coproduzindo significados de mediação nos jardins do Museu da República.

Reafirmando os registros de campo do dia anterior, o estudo notou, sobretudo, a relação existente entre os objetos do mundo dos impressos e do mundo eletrônico-digital, denotando que o livro em formato impresso, o códex, permanece séculos e séculos depois de suas primeiras aparições em coexistência pacífico-simbólica em relação aos demais artefatos.

\section{- Feiras do Centro Histórico da Cidade do Rio de Janeiro sob o enfoque biblioteconômico-informacional}

Para Sato (2012), tendo em vista que algumas feiras são itinerantes, 

Janeiro

elas acabam por ocupar um locus por determinado período de tempo, de modo que o espaço público territorializado assuma outro papel nos dias e períodos em que as feiras não ocorrem. Sendo assim, através da ocupação provisória de um logradouro público, normalmente utilizado por habitantes ou transeuntes, inúmeros significados são criados e recriados no espaço das feiras, originados por meio dessa mudança temporária.

Assim, ao mudar, ainda que temporariamente, os hábitos de determinado espaço, a feira acaba por atribuir novos significados aquele locus e permitir a produção tantos outros, uma vez que diferentes práticas infossociais ocorrem no lugar ou ao lado das antigas (SATO, 2012). E é este o caso das feiras de livro itinerantes do Centro do Rio.

Realizadas, comumente, em praças antes ociosas, no qual as práticas sociais existentes recaíam, em sua maioria, sobre o caminhar apressado dos transeuntes, a instauração de uma feira do livro naquele locus acaba por reiluminar a pluralidade das interações a partir das práticas de compra, de venda e de seleção de livros, as conversas entre livreiros e consumidores.

Nesse sentido, tendo em vista os dados mencionados anteriormente, no ano de 2015, realizou-se a intervenção em uma feira de livro localizada na Praça da Cinelândia, no Centro da Cidade do Rio de Janeiro, no dia 15 de maio. Dispondo de cerca de trinta barracas, divididas entre livros infantis, acadêmicos, antigos, raros, de arte e religião, a feira funcionou, durante um mês, das $8 \mathrm{~h} 30 \mathrm{~min}$ às $20 \mathrm{~h}$, incluindo o ritual de montagem e desmontagem dos stands.

A chegada à feira da Cinelândia se deu por volta das 8 h30min, encontrando livreiros ainda montando suas barracas, e deixamos o espaço ao entardecer, por volta das $18 \mathrm{~h}$. Ao decorrer do dia, foi possível tirar inúmeras fotografias que ilustravam a interação entre artefatos tecnológicos e humanos, bem como realizar entrevistas com os livreiros que tinham seus livros expostos na feira.

Inicialmente, ao realizar a intervenção na feira, tornou-se possível observar a diversidade sociocultural destacada de seu público feirante. Isto é, diferentemente da Primavera dos Livros que, devido à sua localização em um 

Janeiro

lugar de certa imponência econômico-histórica e pela ampla divulgação do evento na mídia, acabou por atrair um público - ainda que diversificado, como relatado - demarcado com traços socioculturais da chamada "zona sul" da Cidade do Rio de Janeiro (incluindo, por exemplo, cidadãos de pele branca, centralmente) -, as feiras itinerantes do Centro apresentam uma multiplicidade no plano das diferenças claramente ampliadas.

Por tratar-se de uma feira que comercializa, em sua maioria, livros usados e antigos a preços baixos, e que encontra-se localizada em uma praça pública do Centro do Rio de Janeiro, junto a uma das estações de metro mais movimentadas do município, onde milhares de pessoas de diferentes culturas, identidades e camadas sociais transitam diariamente, a feira da Cinelândia acaba por atrair tanto bibliófilos quanto uma população diversa, interessados mais na compra de livros baratos do que no espaço de sociabilidade que a feira cria. Além disso, muitas pessoas acabam por visitar a feira apenas pelo fato de estarem passando e indo a outros compromissos no momento em que as mesmas ocorrem, o que acaba, eventualmente, por suscitar o interesse nos livros expostos.

Nesse contexto, sobretudo por não ganhar a mesma divulgação midiática que a Primavera, as feiras itinerantes do Centro atraem um público bem mais diversificado, que acaba por não considerar a feira como um evento em si, mas sim como um espaço para o comércio de livros usados e baratos.

Todavia, no plano da cultura informacional presente nas feiras, as observações realizadas na Feira da Cinelândia se assemelham em muito às percebidas na Primavera dos Livros. Havia um considerável diálogo entre impresso e digital, o qual pôde ser observado através da interação entre indivíduos que portavam celulares e, ao mesmo tempo, conversavam, folheavam e compravam livros, denotando a coexistência entre os artefatos sociotecnológicos.

Além disso, as formas de apropriação dos saberes, através de mediações sociotécnicas - oralidade e gravador, por exemplo -, se deu também por meio das entrevistas realizadas com os livreiros que, ainda que envergonhados diante dos instrumentos de coleta de dados, contavam suas 

Janeiro

histórias sobre como chegaram à feira, afirmando o valor simbólico de suas experiências. Para eles, tendo por base suas vivências e memórias em relação à feira e aos diferentes locus onde ela é realizada, a mesma acaba por suscitar a atribuição de significados já reconhecidos a todos os elementos que compõem o cotidiano do feirante.

Ainda, a conversa entre os livreiros e entre os livreiros e os consumidores e, até mesmo, entre os livreiros e o contato com a pesquisa (principalmente, antes da apresentação dos instrumentos de coleta de dados, ou seja, nos diálogos informais que marcam a silhueta viva da feira), se desenrola na cadência do espaço-tempo feirante como um complexo de mediações sociotécnicas onde o saber é atrelado a uma experiência local da vivência. O próprio modo de olhar, se aproximar, de indagar entre visitante e feirante acaba por apontar para mecanismos de produção e significação do conhecimento das tecnologias da linguagem e, consequentemente, para a percepção de tais dispositivos.

No entanto, na relação entre as duas feiras, registra-se que não havia muitas pessoas fotografando e ou fazendo uso intensivo de aparelhos celulares, tal como visto na Primavera dos Livros, talvez por não considerarem a feira como um evento grandioso ou como um espaço de sociabilidade, talvez pela dinâmica do cotidiano da feira a céu aberto no espaço público de trânsito, talvez pela socialidade oral mais expressa, talvez pelo receio da violência urbana no contexto dos furtos em vias públicas.

Reafirma-se, de qualquer modo, não apenas o diálogo entre 0 eletrônico-digital e o impresso, como também as conversas entre livreiros, a oralidade como outra centralidade, entre o público da feira, o fato de haver bares e pontos turísticos (museus) em torno da mesma, onde as pessoas podiam sentar, comer e beber algo e ainda assim terem uma visão da feira ou, até mesmo, frequentá-la, torna seu locus não apenas em um espaço de interação social, mas também em um elemento simbólico, de significado aberto, daquele espaço, pelo menos durante o período em que permanece ali.

As figuras 5, 6, 7 e 8 ilustram a Feira da Cinelândia como espaço de sociabilidade e locus de interação e mediação social entre artefatos 
sociotécnicos, resultando em atribuição de significados aos elementos previamente reconhecidos na feira.

FIGURAS 5, 6, 7 e 8. Feira de livros itinerante - 15 de maio de 2015 - Praça da Cinelândia

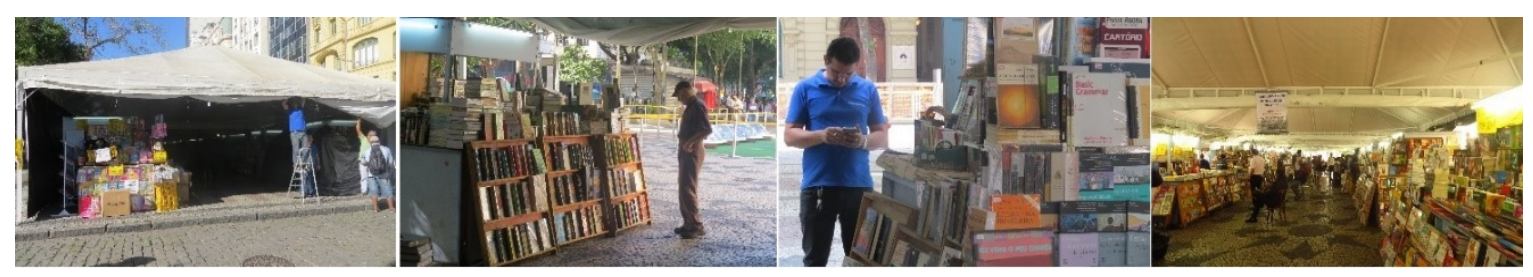

Fonte: Banco de Imagens Ecce Liber

Desse modo, ao observar a circulação dos visitantes da Feira, suas atitudes perante aos seus elementos e a atribuição de significados aos objetos e características já reconhecidos, torna-se possível considerar a Feira do Livro da Cinelândia como uma forma de construção simbólica do Centro do Rio de Janeiro a partir da cultura informacional, uma vez que proporciona a mediação entre o indivíduo e a circulação e apropriação do saber pela via de diferentes artefatos sociotécnicos.

\section{REFLEXÕES FINAIS}

De acordo com Ferraz (2006), a feira do livro encontra sua razão de ser à medida que o seu espaço ultrapassa as fronteiras geográficas, sendo também uma forma de relação com os objetos estruturados em seu locus e, sobretudo, uma rede relacional de representações coletivas, capaz de permitir aos membros de uma mesma coletividade e cultura conceder significados, normalmente reconhecidos, a elementos e características de seu local.

Assim, tendo por base Ferraz (2006) e a experiência nas feiras de livro no Rio de Janeiro, pode-se inferir que a ocupação do espaço propiciada por elas se dá no contexto das interações simbólicas, uma vez que proporciona a relação dos indivíduos com os objetos estruturados na feira, à exemplo do livro, do livreiro, das barracas e, até mesmo, das paisagens. Torna-se possível aos seus frequentadores construir uma rede de significados, geralmente reconhecidos, aos elementos e características do espaço-tempo, sendo o livro 
Amanda Salomão, Gustavo Silva Saldanha

Cultura feirante de informação: um relato de campo sobre as feiras de livro do Rio de Janeiro

e a feira, a oralidade e o olhar, o escutar e o tocar, por exemplo, elementos da construção e da apropriação simbólica do saber para os membros dessa cultura feirante.

Nesse sentido, as feiras de livro do Rio de Janeiro, tanto as promovidas pela Associação Brasileira do Livro quanto a Primavera dos Livros, acabam por ocupar simbolicamente o espaço onde se localizam. A ocupação do espaço por esse evento se dá de uma forma simbólica, propiciando a relação do indivíduo com os objetos presentes na feira, proporcionando aos seus frequentadores atribuírem significados de tal vivência. "Do celular à caneta, dos códices impressos à máquina calculadora, das câmeras de filmagem às câmeras fotográficas de aparelhos móveis, chegamos à comunidades que produzem e significam tais ferramentas." (SALDANHA, 2014, p. 1217).

Há, dessa forma, uma identificação com seus elementos e distintas formas de apropriação do saber nesses locais. Isto é, a circulação do saber existente no ambiente das feiras acaba por propiciar uma obtenção de conhecimento diferente das que ocorrem em bibliotecas e outras unidades de informação. Ao ocupar material e simbolicamente o centro da cidade ou 0 Museu da República, as barracas, os livros, os livreiros, bem como a própria feira, estão atuando como mediadores simbólicos da apropriação do saber.

Conforme aponta Saldanha (2014, p. 1216-1217),

Os elementos centrais identificados e reconhecidos nas feiras, inerentes ao desenvolvimento das relações entre formações simbólicas e mediação, foram as múltiplas e tênues identidades - transidentidades - dos artefatos e de seus 'apropriadores'; a convivência entre a mediação tecnológica e a mediação humana; a coexistência de técnicas e tecnologias da linguagem em diferentes performances no espaço-tempo; as múltiplas materialidades; as distintas formas de ocupação do espaço público pelos agentes e pelos artefatos; a singularidade dos processos de ressignificação da materialidade; as diferentes faixas etárias e 'identidades culturais' dos 'apropriadores'; a virtualidade do simbólico em curso: seu potencial de transformação do mundo.

Com efeito, a mediação, seja ela humana ou tecnológica se dá, primeiramente, de forma simbólica, a partir da linguagem e da cultura. Pode-se inferir que as feiras agem como um ambiente singular de produção, 
organização e disseminação do conhecimento, diferentes daqueles vivenciados em arquivos, museus e bibliotecas, uma vez que o saber e a mediação da informação ocorrem de maneira distinta das formas históricas de tais centros.

\section{REFERÊNCIAS}

ALMEIDA, Marco Antônio de. Mediações da cultura e da informação: perspectivas sociais, políticas e epistemológicas. Tendências da Pesquisa Brasileira em Ciência da Informação, João Pessoa, v. 1, p. 01-24, 2008.

ASSOCIAÇÃO BRASILEIRA DO LIVRO. Disponível em: <http://www.abralivro.com.br/quem-somos.html>. Acesso em: 08 jul. 2015.

FERRAZ, Deise Luiza da Silva. Livros em festa: a cultura organizacional da feira do livro de Porto Alegre. 2006. 193 f. Dissertação (Mestrado em Administração). - Universidade Federal do Rio Grande do Sul, Porto Alegre, 2006.

HORODYSKI, Graziela Scalise. O consumo na experiência turística: o caso dos souvenirs no destino Curitiba-PR. 2014. 443 f. Tese (Doutorado em Geografia). - Universidade Federal do Paraná, Curitiba, 2014.

LEITE, Daniela Carvalho Bezerra. Feiras como espaços de hospitalidade e identidade coletiva: feira permanente da Ceilândia/DF. 2015. $165 \mathrm{f}$.

Dissertação (Mestrado em Turismo) - Universidade de Brasília, Brasília, 2015.

LIBRE. Disponível em: <http://libre.org.br/quem-somos>. Acesso em: 10 nov. 2014.

MARTELETO, Regina Maria. Cultura informacional: construindo o objeto informação pelo emprego dos conceitos de imaginário, instituição e campo social. Ciência da Informação, Brasília, v. 24, n. 1, p. 1-8, 1995. Disponível em: <http://revista.ibict.br/ciinf/article/view/613/615>. Acesso em: 26 out. 2016.

MASSOLA, Gisele. Educação e mídia na cultura sul-rio-grandense: um estudo sobre a Feira do Livro de Porto Alegre. 2015. $281 \mathrm{f}$. Tese (Doutorado em Educação) - Universidade Federal do Rio Grande do Sul, Porto Alegre, 2015.

MAZZAROTTO, Angelo Augusto Valles de Sá. Agricultura ecológica e seu papel na reconstrução da ética ambiental. 2014. 194 f. Tese. (Doutorado em Sociologia) - Universidade Federal do Paraná, Curitiba, 2014. 
Amanda Salomão, Gustavo Silva Saldanha

Cultura feirante de informação: um relato de campo sobre as feiras de livro do Rio de Janeiro

RETIERE, Morgane Isabelle Helene. Agricultores inseridos em circuitos curtos de comercialização: modalidades de venda e adaptações dos sistemas agrícolas. 2014. 115 f. Dissertação (Mestrado em Ciências) Universidade de São Paulo, Piracicaba, SP, 2014.

REVISTA DO LIVRO. Rio de Janeiro: Instituto Nacional do Livro, v. 10, n. 31, 1967.

SALDANHA, Gustavo Silva. Mediação e formações simbólicas: notas cassirerianas sobre linguagem, conhecimento e cultura na Ciência da Informação. In: ENCONTRO NACIONAL DE PESQUISA EM CIÊNCIA DA INFORMAÇÃO, 15., 2014, Belo Horizonte. Anais... Belo Horizonte, 2014. p. 1202-1221.

SATO, Leny. Feira livre: organização, trabalho e sociabilidade. São Paulo: Edusp, 2012.

TONET, Rogério Silveira. Fenonomias, economia plural e desenvolvimento local: um estudo da feira de artesanato do Largo da Ordem em Curitiba - PR. 2004. 160 f. Dissertação (Mestrado em Administração) - Universidade Federal do Paraná, Curitiba, 2004.

VASCONCELLOS, lara Grotz Moreira de. Sistemas de atividades na divulgação científica universitária. 2015. 150 f. Dissertação (Mestrado em Ensino de Biologia) - Programa Interunidades de Ensino de Ciências, Universidade de São Paulo, São Paulo, 2015.

\title{
AGRADECIMENTO
}

Este trabalho foi desenvolvido sob o apoio da Fundação Carlos Chagas Filho de Amparo à Pesquisa do Estado do Rio de Janeiro (FAPERJ).

\section{Title}

Informational bookfair culture: experiences about the Rio de Janeiro bookfairs

\begin{abstract}
Introduction: it is considered the universe of book fairs as spaces that provide not only the democratization and encouragement of books and reading, but also informational practices through human and technological appropriation and mediation of knowledge, resulting in an information culture at the locus of the bookfairs. Objective: to analyze the relation between symbolic occupation and circulation and appropriation of knowledge from two bookfairs in Rio de Janeiro: Primavera dos Livros, promoted by the Liga Brasileira de Editoras (LIBRE) and the bookfairs of the Associação Brasileira do Livro (ABL). Methodology: intervention, in the years of 2014 and 2015, on the two fairs mentioned, based on the contributions of the ethnographic method. It attempted to
\end{abstract}



Janeiro

observe the practices and informational exchanges that took place on the show floor, emphasizing the human and technological mediations experienced by its objects and actors. Result: the occupation of the space afforded by book fairs is given in symbolic form, as it provides a list of individuals with structured objects in the fair locus. It became possible to its visitors assign a network of meanings to the elements and characteristics of space, and the book and the show, for example, objects symbolic appropriation of knowledge for the members of that bookfairs culture. Conclusion: the bookfairs act as a new production environment, organization and dissemination of knowledge, different from those experienced in archives, museums and libraries, since the knowledge and information mediation occur differently to the traditional way.

Keywords: Bookfair. Informational bookfair culture. Mediation. Sociotechnical artifact. Cultural information.

\section{Título}

Cultura feriante de información: un relato de campo sobre las ferias del libros de Rio de Janeiro

\section{Resumen}

Introducción: se considera el universo de las ferias del libro como espacios que proporcionan no sólo la democratización y la promoción del libro y de la lectura, así como, las prácticas de información a través de la propiedad y la mediación humana y tecnológica del conocimiento, lo que resulta en una cultura de la información en el locus de las ferias. Objetivo: analizar la relación entre la ocupación simbólica y la circulación y apropiación del conocimiento de dos ferias del libro de Rio de Janeiro: Primavera dos Livros, promovidas por la Liga Brasileira de Editoras (LIBRE) y la iniciativa de las ferias del libro de la Associação Brasileira do Livro (ABL). Metodología: intervención en los años 2014 y 2015, en las dos ferias mencionadas, con base en las contribuciones del método etnográfico. Él trató de observar las prácticas y los intercambios de información que tuvieron lugar en el salón, haciendo hincapié en las mediaciones humanas y tecnológicas experimentadas por sus objetos y actores. Resultado: la ocupación del espacio proporcionado por las ferias del libro se da en forma simbólica, ya que proporciona una lista de personas con objetos estructurados en el lugar justo. Se hizo posible a sus visitantes a asignar una red de significados a los elementos y características del espacio, y el libro y el espectáculo, por ejemplo, objetos de apropiación simbólica del conocimiento de los miembros de esa cultura vendedor. Conclusión: las ferias actúan como otro entorno de producción, organización y difusión de los conocimientos, diferentes de aquellos experimentados en archivos, museos y bibliotecas, ya que el conocimiento y la mediación de información se producen de manera diferente a la manera tradicional.

Palabras Clave: Feria del libro. Cultura feriante de información. Mediación. Artefacto sociotécnico. Cultural informacional.

Recebido em: 16.11.2016

Aceito em: 04.12.2017 